\title{
A femoral component with proximal HA coating
}

\author{
AN ANALYSIS OF SURVIVAL AND FIXATION AT UP TO TEN YEARS
}

J. A. Skinner, P. O. Kroon, S. Todo, G. Scott

From the Royal National Orthopaedic Hospital and the Royal London Hospital NHS Trust, London, England

$\mathbf{W}^{\mathrm{c}}$ e describe the survival at ten years of 100 femoral components of the Freeman hip prosthesis. It is proximally hydroxyapatite (HA)-coated and was fixed without cement. Radiological assessment identified radiolucent lines (RLLs) and lytic lesions and was used to measure migration.

The criterion of failure was revision or impending revision for aseptic femoral loosening. No femoral components were revised or are awaiting revision for aseptic loosening, giving $\mathbf{1 0 0 \%}$ survival at ten years (95\% confidence interval, 95.7 to 100), although 59 were at risk at ten years. Two components were revised for fracture of a ceramic head with damage to the trunnion. Although well fixed in each, for survival analysis we evaluated the hip as if the patient had died.

Twelve acetabular components were revised and at each operation the femoral component was found to be well fixed, was not disturbed and remained in the survival analysis. Three patients were lost to follow-up, and 12 died with well-functioning prostheses.

Radiologically, all except one of the components appeared to be well fixed with no RLLs and no lytic lesions at the latest follow-up. The mean vertical migration was $0.4 \mathrm{~mm}$ at one year, $0.8 \mathrm{~mm}$ at two years and $1.4 \mathrm{~mm}$ at ten years. One component had migrated

J. A. Skinner, FRCS (Orth), Senior Lecturer and Honorary Consultant Orthopaedic Surgeon

Royal National Orthopaedic Hospital, Brockley Hill, Stanmore, Middlesex, HA7 4LP, UK

P. O. Kroon, MD, Consultant Orthopaedic Surgeon

Alingsas Hospital, Alingsas, Sweden.

S. Todo, MD, Research Fellow

Department of Orthopaedic Surgery, Osaka City University Medical School, Abeno-Ku, Asdahinachi, 1-4-3 Osaka, 545-8585, Japan.

G. Scott, FRCS, Consultant Orthopaedic Surgeon

The Royal London Hospital, Whitechapel Road, London E1 4DG, UK.

Correspondence should be sent to Mr J. A. Skinner.

(C2003 British Editorial Society of Bone and Joint Surgery doi.10.1302/0301-620X.85B3.13054 \$2.00
$7.6 \mathrm{~mm}$ at ten years $(2.1 \mathrm{~mm}$ in year 1$)$ and developed RLLs in Gruen zones I and II. The symptoms, however, were only minor and revision was not indicated.

Our study has shown that proximal HA coating gives effective fixation for a femoral component.

J Bone Joint Surg [Br] 2003;85-B:366-70.

Received 4 December 2001; Accepted after revision 4 September 2002

The outcome has previously been reported of the use of the Freeman femoral component in total hip arthroplasty (THA) with four methods of fixation namely cement, hydroxyapatite (HA), ${ }^{1}$ and two varieties of press-fit. The results for cement and HA were the same and both were better than for those with a press-fit. The cemented version had results at ten years, but only mid-term evaluation was available for the HA component. We now report an independent review of the radiological and clinical outcome of the HA-coated version of this component at ten years.

The survival at ten years for other HA-coated femoral components has been reported to range from $99 \%$ to $100 \%{ }^{2-4}$ with radiological evidence of sound fixation, few radio-lucent lines (RLLs) and little or no osteolysis. Two of these series involved proximally-coated components. Our data therefore represent the third such consecutive series to be reported at ten years. It differs in that when using this component the femoral neck is retained in an effort to control longitudinal rotation.

\section{Patients and Methods}

We included the first 100 patients who received a proximally HA-coated Freeman femoral component (Finsbury Instruments, Leatherhead, UK and Corin, Cirencester, UK) during a THA and who were available for review. The same surgical team carried out all the operations between January 1989 and March 1992. Initially, the indication for cementless fixation was age less than 60 years, but this age limit was later relaxed. Details of the patients are given in Table I. All procedures were primary arthroplasties.

The prosthesis. The prosthesis is unconventional in that the femoral neck is retained. It was initially made of titanium alloy but, more recent versions are of cobalt-chrome. It is proximally shot-blasted to give a surface roughness of $3 \mu \mathrm{m}$ 


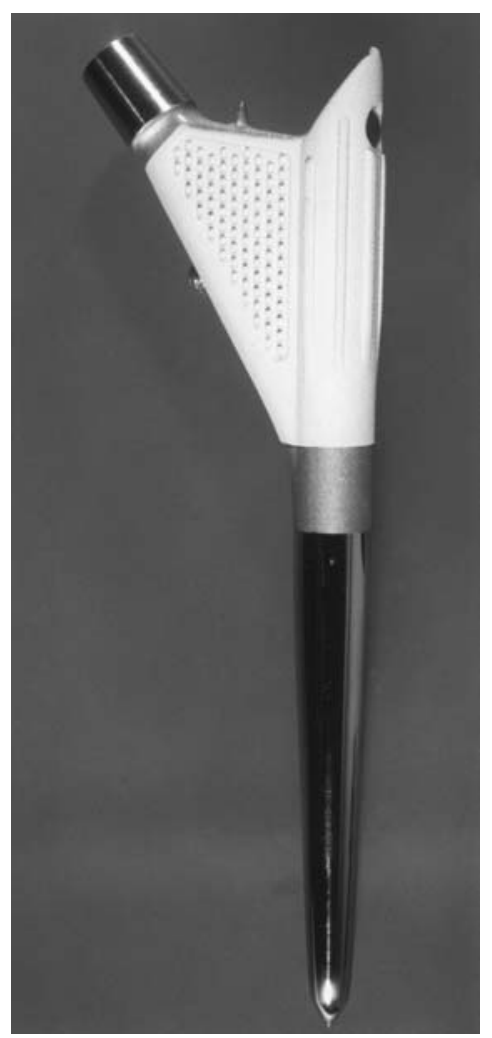

Fig. 1a

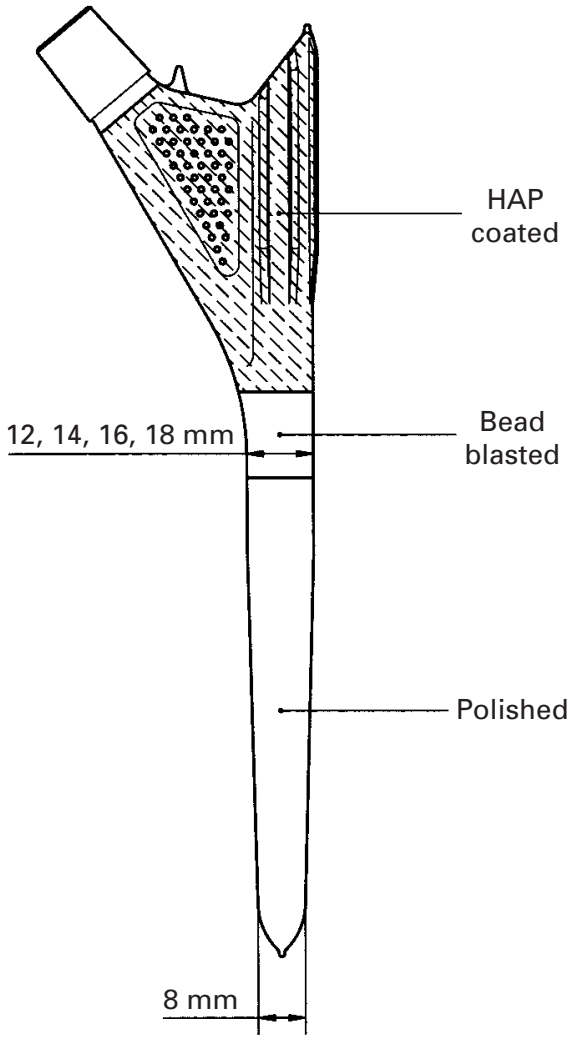

Fig. 1b

Photograph a) and diagram b) of the Freeman HA-coated prosthesis. The maximum diameters of the stem and the superolateral projection on the prosthesis for the measurement of migration are shown.

Ra, with added ridges and cast-in stipples (Fig. 1). Distally, the stem is polished, tapered and circular in cross-section. The HA coating, which induces ingrowth ${ }^{5}$ is applied proximally by plasma spray (Plasma Biotal Ltd, Tideswell, UK) to a thickness of 80 to $120 \mu \mathrm{m}$.

Operative technique. Using an anterolateral approach, we introduced a straight, tapered reamer, circular in crosssection, into the canal by hand. ${ }^{6}$ No attempt was made to press-fit the stem in the femoral diaphysis. The maximum dia-meter of the stem was $14 \mathrm{~mm}$ for small femoral canals and $16 \mathrm{~mm}$ for larger canals. The retained femoral neck had a slot cut in it to receive the collarless neck of the prosthesis. The possible mechanical advantage of retaining the femoral neck has been reported elsewhere, ${ }^{7}$ but it should be noted that retaining it increases the surface area of bone which is in contact with the HA coating, by lengthening zones I and VII of Gruen, McNeice and Amstutz. ${ }^{8}$ As the prosthesis is driven into the femur, the proximal ridges and stipples on the neck cut into the cancellous bone.

All patients were mobilised non-weight-bearing for the first six weeks and partially weight-bearing for a further six weeks. All received indomethacin (75 $\mathrm{mg}$ twice daily) for between two and ten days as prophylaxis against heterotopic bone formation.
Table I. Details of the 100 patients who received a THA which included an HA-coated femoral prosthesis

\begin{tabular}{lc}
\hline & Number of patients \\
\hline Total & 100 \\
$\quad$ Male & 58 \\
Female & 42 \\
Mean age (in years) & \\
$\quad<60$ & 74 \\
$>60$ & 26 \\
Diagnosis & \\
$\quad$ Osteoarthritis & 70 \\
Rheumatoid arthritis & 7 \\
Post-traumatic & 14 \\
Other & 9 \\
\hline
\end{tabular}

Radiological review. Orthopaedic surgeons reviewed the patients after six months, and then at one, two, three, five, seven and ten years using standard data capture sheets. At each visit a standardised anteroposterior (AP) radiograph was taken. This was centred on the greater trochanter and showed the whole of the component in order to allow measurement of vertical downward migration. ${ }^{9}$ We did not use lateral radiographs because such views are not repeatable from year to year and therefore, for example, sequential measurement of radiolucent lines (RLLs) is not possible. 
Table II. Life table with criterion for failure defined as revision or impending revision for aseptic femoral loosening

\begin{tabular}{lllllllllll}
\hline $\begin{array}{l}\text { Years } \\
\text { since } \\
\text { operation }\end{array}$ & $\begin{array}{l}\text { Start } \\
\text { number }\end{array}$ & Failures & Died & $\begin{array}{l}\text { Lost to } \\
\text { follow-up }\end{array}$ & $\begin{array}{l}\text { Revised not completed At risk } \\
\text { failed* }\end{array}$ & $\begin{array}{l}\text { Not } \\
\text { the year }\end{array}$ & $\begin{array}{l}\text { Cumulative } \\
\text { survival } \\
\text { (\%) }\end{array}$ & $\begin{array}{l}\text { Confidence limit } \\
\text { Upper } \\
\text { (\%) }\end{array}$ & $\begin{array}{l}\text { Lower } \\
\text { (\%) }\end{array}$ \\
\hline 0 to 1 & 100 & 0 & 2 & 0 & 0 & 0 & 99.0 & 100 & 100.0 & 96.3 \\
1 to 2 & 98 & 0 & 0 & 0 & 0 & 0 & 98.0 & 100 & 100.0 & 96.2 \\
2 to 3 & 98 & 0 & 0 & 0 & 0 & 0 & 98.0 & 100 & 100.0 & 96.2 \\
3 to 4 & 98 & 0 & 1 & 0 & 1 & 0 & 97.0 & 100 & 100.0 & 96.2 \\
4 to 5 & 96 & 0 & 2 & 1 & 1 & 0 & 94.0 & 100 & 100.0 & 96.2 \\
5 to 6 & 92 & 0 & 1 & 1 & 0 & 0 & 91.0 & 100 & 100.0 & 96.2 \\
6 to 7 & 90 & 0 & 3 & 0 & 0 & 0 & 88.5 & 100 & 100.0 & 96.1 \\
7 to 8 & 87 & 0 & 2 & 0 & 0 & 7 & 82.5 & 100 & 100.0 & 96.1 \\
8 to 9 & 78 & 0 & 1 & 1 & 0 & 12 & 71.0 & 100 & 100.0 & 95.9 \\
9 to 10 & 64 & 0 & 0 & 0 & 0 & 9 & 59.5 & 100 & 100.0 & 95.7 \\
\hline
\end{tabular}

*these prostheses were not loose either radiologically or at operation. They were revised because the trunnion was damaged after fracture of the ceramic head

Since we used a separate pelvic film to assess the acetabular component (not reported here) there was also a need to limit the exposure to radiation.

Two observers (JAS, POK) sought RLLs and other radiological features at two, five and ten years or on the latest available radiograph. The definition of an RLL was a linear lucency at the bone-component interface, which was $2 \mathrm{~mm}$ wide and occupied at least $30 \%$ of any one Gruen zone. ${ }^{8}$ Lytic lesions are balloon-shaped lucencies without sclerosis. Reactive lines were defined as RLLs of thickness of $<1 \mathrm{~mm}$ as described by Engh, Massin and Suthers. ${ }^{10}$ They were seen usually around the polished part of the stem. Their histological examination has shown fine fibrous tissue devoid of macrophages and debris. ${ }^{11}$

Measurement of migration. The technique for measuring the vertical migration of the component within the femur has been previously described. ${ }^{1,8,12}$ A digitiser measured the distance between the tip of the greater trochanter and the projection on the proximal/lateral shoulder of the component (Fig.1). This distance minus the same distance on the postoperative radiograph was the migration distance.

Survival analysis. We produced a life table with confidence intervals using the Rothman formula. ${ }^{13,14}$ The criterion for failure was revision or impending revision of the femoral component for aseptic loosening.

\section{Results}

Patients lost to follow-up. Other studies have shown that the number of patients lost to follow-up may have a significant effect on the results of studies such as ours. ${ }^{14,15}$ Three patients moved and were lost to review with well-functioning hips after five, six and nine years. They are known not to have died in the UK since their deaths are not registered with the Office of National Statistics. Their radiological findings are included as at their latest review as are those of the 12 patients who died of unrelated causes with well-functioning hips.

Revision procedures. Revisions of two well-fixed femoral components were due to fractures of their ceramic heads causing damage to the trunnion. Using a special saw (Tuke
Saw; Finsbury Instruments, Leatherhead, UK) the HA interface was cut from above to allow the component to be removed. For the purposes of the survival analysis we treated these hips as if the patient had died and are shown as 'revised not failed' in Table II. Of the 12 further hips which underwent revision, ten were for acetabular loosening, one for periprosthetic femoral fracture and one for fracture of a ceramic head without damage to the trunnion. The femoral components of these hips appeared to be well fixed radiologically and this was confirmed at operation. None was revised and they remain under review.

Thus, these femora represent a group of particular interest since their fixation was determined by direct examination of the interface rather than solely by inference from radiographs. The findings in these hips were the same as those in the two which were removed; neither a gap nor relative movement could be detected between the femur and the component. Radiologically, these components had migrated by a mean of $1.4 \mathrm{~mm}$ at the time of the revision, a migration which was similar to that in the group which did not undergo revision. No interfaces displayed an RLL or a lytic lesion. Six interfaces had reactive lines in zones III, IV, V. At the time of this review, these femoral components had remained radiologically unchanged after the acetabular revision for a mean of 2.58 years ( 0.17 to 9.08$)$.

The interface in the patient with a traumatic periprosthetic fracture was also observed at operation when the loose acetabular component was revised. The femoral component was well fixed and the fracture was treated by a cable plate system and healed uneventfully.

Survival analysis. Table II gives the details; 64 hips were reviewed at ten years making the survival analysis statistically valid. Revision or impending revision for aseptic loosening of the femoral component was used as the criterion of failure. Since there were no femoral revisions, the survival was $100 \%$ (95\% CI 95.7 to 100). If the three patients who were lost to follow-up but who were clinically and radiologically satisfactory at their latest review, are regarded as failures, this figure falls to $96.6 \%$ (95\% CI 90.4 to 98.9 ).

Migration. One femoral component migrated $7.6 \mathrm{~mm}$ over ten years and developed RLLs in zones I and II. During the 
Table III. Mean distal migration (mm) seen in the 100 hips after THA with a follow-up of up to ten years

\begin{tabular}{llll}
\hline & \multicolumn{3}{c}{ Mean distal migration $(\mathbf{m m})$} \\
\cline { 2 - 4 } Follow-up & $\begin{array}{l}\text { All hips } \\
(\mathbf{n}=\mathbf{1 0 0})\end{array}$ & $\begin{array}{l}\text { Hips with } \\
\text { radiographs } \\
\text { for 10 years } \\
(\mathbf{n}=\mathbf{5 4})\end{array}$ & $\begin{array}{l}\text { Hips with RLLs } \\
(\mathbf{n}=\mathbf{1})\end{array}$ \\
\hline 1 & 0.4 & 0.4 & 2.1 \\
2 & 0.8 & 0.7 & 2.6 \\
10 & 1.4 & 1.4 & 7.6 \\
\hline
\end{tabular}

Table IV. Number of hips with site of 'reactive' lines by Gruen zone

\begin{tabular}{lc}
\hline Gruen zone & Number of hips \\
\hline I & 1 \\
II & 3 \\
III & 5 \\
IV & 9 \\
V & 25 \\
VI & 7 \\
VII & 0 \\
\hline
\end{tabular}

first year it migrated $2.1 \mathrm{~mm}$. Thereafter, the mean rate of migration was $0.6 \mathrm{~mm} / \mathrm{year}$ with recently a trend towards a slower rate. This hip has not been revised since the symptoms do not merit it and the radiological changes are not progressing.

The migration of the remaining components is shown in Table III. The mean migration was less than $0.1 \mathrm{~mm} / \mathrm{year}$ after two years. We do not believe that this rate has fallen to zero in the group as a whole, although using a method with an observer error of $\pm 1 \mathrm{~mm}$, we cannot be sure of this. ${ }^{8}$

Radiolucent lines and lytic lesions. The one component which migrated rapidly had RLLs of $2 \mathrm{~mm}$ extending for more than $30 \%$ of zones I and II. These lines appeared during the period of high initial migration and have not progressed since. No other RLLs and no lytic lesions were seen.

Reactive lines. Reactive lines were seen in 50 hips (Table IV), in $78 \%$ of which they were related to the polished, distal part of the stem (Gruen zones III, IV and V). As has been previously reported such lines were neither progressive nor symptomatic and were not associated with features of failed fixation. ${ }^{10}$

Condensations of bone. 'Spot welds' or trabecular 'streaming' of bone on to the proximal part of the prosthesis were seen in $83 \%$ of hips (Fig. 2). These features were either medial, lateral or both. In the $17 \%$ in which they were not seen, there was trabecular bone closely applied to the proximal part of the prosthesis, but without trabecular reorientation.

\section{Discussion}

We have described the outcome of an HA-coated femoral component of a hip arthroplasty using criteria which have

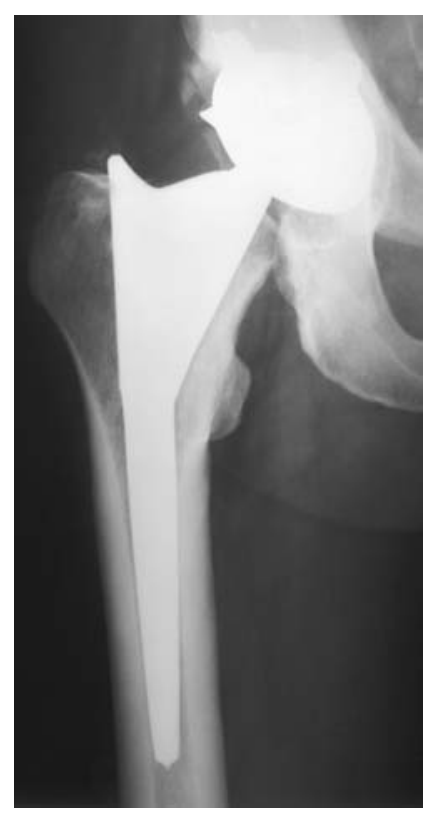

Fig. 2a

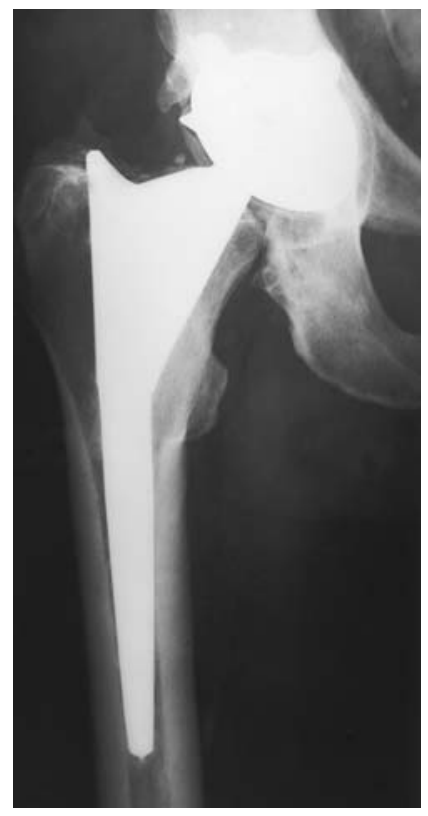

Fig. 2b
Radiographs a) immediately after operation and b) after ten years. There is trabecular 'streaming' of bone onto the prosthesis in zone II.

been used elsewhere. ${ }^{1,8,12}$ The reporting of the outcome of a single component is valid. ${ }^{16,17}$ If we had discussed the outcome of the arthroplasty as a whole, the survival would have been lower because of acetabular loosening and fracture of the ceramic head. Three of $46(6.5 \%)$ alumina ceramic heads fractured.

By selection at the outset, the patients were younger, with a mean age of 56.8 years; $75 \%$ were below the age of 60 years compared with those in a previously reported group for the same component fixed with cement (mean age 68.8 years, none below the age of 60 years). ${ }^{1}$ The results may have been expected to be worse but were better for survival at ten years $(10 \% v 97 \%)$, mean distal migration $(0.14$ $v 0.34 \mathrm{~mm} /$ year), presence of RLLs at five years (1\% v 8\%) and presence of lytic lesions at five years $(0 \% v 5 \%)$.

As shown previously, the criteria which were used for RLLs, lytic lesions and vertical loosening are reliable indicators of aseptic femoral loosening. ${ }^{10}$ The findings at two years predicted the outcome at ten years, thus adding weight to the prediction process proposed by Kobayashi et al. ${ }^{18}$ The National Institutes of Health consensus group ${ }^{19}$ has stated that only implants with $95 \%$ survival at ten years can be considered to be satisfactory. In our series the survival figure of $100 \%$ includes three femoral components which were lost to follow-up and included as 'not revised'. If they are included as 'revised', the worst-case survival becomes $96.6 \%$, which still exceeds the standard required for current femoral components. ${ }^{19}$

The presence of 'reactive lines', as distinct from RLLs, around $50 \%$ of components and of significant migration in 
one component could be cited as evidence of less than perfect femoral fixation. We have previously reported the incidence of 'reactive lines' with this HA-coated prosthesis, but these were not recorded in the cemented series offered for comparison, because they are hard to detect against an interface of cement. ${ }^{1}$ We agree with others that these non-progressive, reactive lines are of no clinical significance. ${ }^{10}$ They are histologically inert, and are usually seen around the uncoated part of the stem. ${ }^{11}$ We confirmed the occurrence of secure fixation in some of these hips with reactive lines by direct inspection of the interface during revision procedures, which were required for reasons mainly related to the acetabular component.

In one hip, initial fixation by HA failed, and there was distal migration of the femoral component of $2.1 \mathrm{~mm}$ in one year, but it has not required revision. Although immediate on-growth obviously did not occur, secondary press-fit fixation has been satisfactory for a further nine years with the development of minimal symptoms, non-progressive RLLs in two zones and a mean migration from years one to ten of $0.6 \mathrm{~mm} /$ year. The pattern of migration in this hip resembles that of the same prostheses implanted without HA, in which revision was not required by ten years, but in which RLLs developed. ${ }^{1}$ Presumably, all these prostheses, and the one reported here, did not have direct apposition of bone, but acquired sufficiently secure press-fit fixation to allow survival for ten years.

Our findings with regard to survival at ten years and RLLs are similar to those with other proximally-coated and fully-coated femoral components. ${ }^{2-4}$ It would seem that HA interfaces afford a barrier to the distal migration of wear debris, as shown by the rarity of lytic lesions reported here and in the other three series. All these studies record better results than those achieved with cement, and, in our study, by the same surgeons using the same prosthesis. Taken together, the published results with HA include all age groups. It therefore seems that HA coating, on a suitably designed femoral component, may provide more secure fixation than does cement.

There has been some anxiety with regard to the possible degradation of HA in the biological environment and that if this occurs, the prosthesis will become loose. Our study over ten years shows no evidence of this. Neither the radiological appearance nor the rate of migration has deteriorated with time.

Two caveats must be mentioned. First, the results cannot be extrapolated to other implants such as acetabular components. Secondly, the literature suggests that if a surgeon attempts to obtain a tight press-fit, he may occasionally induce a femoral fracture. ${ }^{2}$ Our series suggests that attempts to achieve tight cortical contact may be unnecessary. We did not rely on impacting the stem of the component into the femoral canal distal to the lesser trochanter in order to achieve fixation. This part of the prosthesis is circular and polished and may play little part in fixation. On the contrary, we believe that fixation depends on the shape and HA coating of that part of the prosthesis which is in direct contact with the proximal cancellous bone, including that in the femoral neck. A prosthesis fixed in this way is neither more difficult nor more time-consuming to implant than is a conventional hemiarthroplasty for subcapital fracture of the femoral neck.

We wish to acknowledge Mr M. A. R. Freeman, FRCS, for allowing us to study his patients and for his support and encouragement throughout the preparation of this text. Mrs C. Connolly provided invaluable help in managing the database and facilitating patient follow-up. Miss H. Yeo carried out all measurements of prosthesis migration. The Department of Health provided Mrs Connolly's salary as part of a prospective arthroplasty followup project.

No benefits in any form have been received or will be received from a commercial party related directly or indirectly to the subject of this article.

\section{References}

1. Donnelly WJ, Kobayashi A, Freeman MAR, et al. Radiological and survival comparison of four methods of fixation of a proximal femoral stem. J Bone Joint Surg [Br] 1997;79-B:351-60.

2. McNally SA, Shepperd JAN, Mann CV, Walczak JP. The results at nine to twelve years of the use of a hydroxyapatite-coated femoral stem. J Bone Joint Surg [Br] 2000;82-B:378-82.

3. Capello WN, D’Antonio JA, Manley MT, Feinberg JR. Hydroxyapatite in total hip arthroplasty: clinical results and critical issues. Clin Orthop 1998;355:200-11.

4. McLaughlin JR, Lee KR. Total hip arthroplasty with an uncemented femoral component: excellent results at 10-year follow-up. J Bone Joint Surg [Br] 1997;79-B:900-7.

5. Stephenson PK, Freeman MAR, Revell PA, et al. The effect of hydroxyapatite coating on ingrowth of bone into cavities in an implant. J Arthroplasty 1991;6:51-8.

6. Stephenson PK, Freeman MAR. Exposure of the hip using a modified anterolateral approach. J Arthroplasty 1991;6:137-45.

7. Albrektsson BEJ, Freeman MAR, Carlsson LV, Tuke MA, Clark JM. Retention of the femoral neck: a method to enhance prosthetic fixation. J Orthop Surg Techn 1987:99-123.

8. Gruen TA, McNeice GM, Amstutz HC. "Modes of failure" of cemented stem-type femoral components: a radiographic analysis of loosening. Clin Orthop 1979;141:17-27.

9. Braud P, Freeman MAR. The effect of retention of the femoral neck and of cement upon the stability of a proximal femoral prosthesis. $J$ Arthroplasty 1990;5:5-10.

10. Engh CA, Massin P, Suthers KE. Roentgenographic assessment of the biologic fixation of porous-surfaced femoral components. Clin Orthop 1990;257:107-28.

11. Revell P, Freeman MAR. Bone-cement and bone-cobalt chrome interfaces in the same well-fixed knee arthroplasty components. J Arthroplasty: in press.

12. Kroon P-O, Freeman MAR. Hydroxyapatite coating on hip prostheses: effect on migration into the femur. J Bone Joint Surg [Br] 1989;71$\mathrm{B}: 452-5$.

13. Murray DW, Carr AJ, Bulstrode C. Survival analysis of joint replacement. J Bone Joint Surg [Br] 1993;75-B:697-704.

14. Ferdinand RD, Pinder IM. Survival analysis of joint replacement. $J$ Bone Joint Surg [Br] 1997;79-B:878.

15. Murray DW, Britton AR, Bulstrode CJK. Loss to follow-up matters. J Bone Joint Surg [Br] 1997;79-B:254-7.

16. Galante J. Editorial. Evaluation of results of total hip replacement. $J$ Bone Joint Surg [Am] 1990;72-B:159-60.

17. Poss R, Clark CR, Heckman JD. A concise format for reporting the longer-term follow-up status of patients managed with total hip arthroplasty. J Bone Joint Surg [Am] 2001;83-A:1779-81.

18. Kobayashi A, Donnelly W, Scott G, Freeman MAR. Early radiological observations may predict the long-term survival of femoral hip prostheses. J Bone Joint Surg [Br] 1997;79-B:583-9.

19. National Institutes of Health. Total hip replacement. NIH Consens Statement 1994;12:1-31. 